\title{
Complex coding of endogenous siRNA, transcriptional silencing and H3K9 methylation on native targets of germline nuclear RNAi in C. elegans
}

Julie Zhouli Ni, Esteban Chen and Sam Guoping Gu*

\begin{abstract}
Background: Small RNA-guided transcriptional silencing (nuclear RNAi) is fundamental to genome integrity and epigenetic inheritance. Despite recent progress in identifying the capability and genetic requirements for nuclear RNAi in Caenorhabditis elegans, the natural targets and cellular functions of nuclear RNAi remain elusive.

Methods: To resolve this gap, we coordinately examined the genome-wide profiles of transcription, histone $\mathrm{H3}$ lysine 9 methylation (H3K9me) and endogenous siRNAs of a germline nuclear Argonaute (hrde-1/wago-9) mutant and identified regions on which transcription activity is markedly increased and/or H3K9me level is markedly decreased relative to wild type animals.

Results: Our data revealed a distinct set of native targets of germline nuclear RNAi, with the H3K9me response exhibiting both overlapping and non-overlapping distribution with the transcriptional silencing response. Interestingly LTR retrotransposons, but not DNA transposons, are highly enriched in the targets of germline nuclear RNAi. The genomic distribution of the native targets is highly constrained, with $>99 \%$ of the identified targets present in five autosomes but not in the sex chromosome. By contrast, HRDE-1-associated small RNAs correspond to all chromosomes. In addition, we found that the piRNA pathway is not required for germline nuclear RNAi activity on native targets.
\end{abstract}

Conclusion: Germline nuclear RNAi in C. elegans is required to silence retrotransposons but not DNA transposon. Transcriptional silencing and H3K9me can occur independently of each other on the native targets of nuclear RNAi in C. elegans. Our results rule out a simple model in which nuclear Argonaute protein-associated-small RNAs are sufficient to trigger germline nuclear RNAi responses. In addition, the piRNA pathway and germline nuclear RNAi are specialized to target different types of foreign genetic elements for genome surveillance in C. elegans.

Keywords: Nuclear RNAi, piRNA, Endo-siRNA, Transcriptional silencing, Heterochromatin, Argonaute protein, Retrotransposon silencing, Germline, ChIP-seq, Pre-mRNA-seq

\footnotetext{
* Correspondence: ggu@dls.rutgers.edu

Department of Molecular Biology and Biochemistry, Rutgers the State

University of New Jersey, Nelson Labs A125, 604 Allison Road, Piscataway, NJ 08854, USA
} 


\section{Background}

RNA interference (RNAi) was originally discovered as a biochemical pathway triggered by double-stranded RNA (dsRNA) that leads to degradation of target mRNA with the corresponding sequence $[1,2]$. RNAi is initiated by cutting dsRNA into small RNAs of 20-30 nucleotides (called small interfering RNAs, or siRNAs) by the RNase III-like enzyme dicer [3]. The resulting siRNAs are loaded into the highly conserved Argonaute (AGO) family of RNA-binding proteins, defined by the PIWI and PAZ domains [4]. Target mRNAs, through their base-pairing interactions with siRNAs, can then be degraded by the endonucleolytic activity ('slicer') of Argonaute proteins [5-7]. In plants, fungi, and C. elegans, dicer-produced siRNAs (named primary siRNAs) can also trigger de novo synthesis of additional small RNAs (called "secondary siRNAs") through recruitment of RNA-directed RNA polymerases (RdRPs) that use the mature target mRNA as a template [8-10]. Endogenous small RNAs that are antisense to transcripts also exist in a variety of eukaryotic species. These so-called endo-siRNAs modulate a diverse set of cellular processes, such as gene expression, genome surveillance, chromosome transmission, and behavior adaptation [11-19].

In addition to mRNA degradation, RNAi has been found to function in the nucleus of plants and Schizosaccharomyces pombe. Nuclear siRNAs in these organisms guide Argonaute proteins and other protein factors to silence transcription and form a repressive chromatin state on target genes [reviewed in [20-23]]. This process has been termed "nuclear RNAi" (reviewed in [24]), as distinguished from the RNA-triggered mRNA degradation mechanism, referred to as "classical RNAi".

Recent studies in Drosophila and C. elegans demonstrated that nuclear RNAi mechanisms play crucial functions in animals as well. In Drosophila, three PIWI subfamily members of Argonaute proteins, AGO3, Aubergine, and Piwi, in concert with PIWI-associated small RNAs (piRNAs) guide molecules, silence transposons in both somatic and germ cells [25,26]. Gene silencing mediated by AGO3 and Aubergine occurs at the post-transcriptional level [26], while the Piwi protein leads to transcriptional silencing and heterochromatin response on its target transposons [27-29].

Nuclear RNAi in C. elegans was initially suggested by the reduction of target transcripts in the nucleus when animals were treated with exogenous dsRNA (exo-dsRNA) [30]. Recent studies using genetics, biochemistry, and whole-genome approaches demonstrated that exo-dsRNA triggers transcriptional silencing as well as H3K9 methylation (H3K9me), a histone mark associated with the repressive chromatin state [31-34], on the target loci [35-39]. A diverse set of protein-coding genes was found to be susceptible to exo-dsRNA-induced nuclear RNAi [36,39]. These features, combined with powerful genetics, make C. elegans a highly attractive system to study the mechanisms of nuclear RNAi. Several genes, including nrde-1, -2, -3, and -4 , have been recently identified for their essential roles in the nuclear RNAi pathway [35-37].

Nuclear RNAi in C. elegans is a bona fide epigenetic process. For a number of germline-expressed genes, the exo-dsRNA-induced silencing state, as well as targetspecific H3K9 trimethylation, can last for several generations [39]. The epigenetic inheritance of the RNAi effects is dependent on the nuclear RNAi pathway. Recent studies identified HRDE-1, a nucleus-localized Argonaute protein, for its essential role in heritable RNAi [38,40,41]. HRDE-1 is one of several worm-specific AGO proteins and was initially named as WAGO-9 [42]. The name HRDE-1 is used in this work to reflect the heritable RNAideficient phenotype of the mutant. HRDE-1 is highly expressed in the $C$. elegans germline and appears to be absent in somatic cells, so it is considered as a germlinespecific nuclear Argonaute protein. In contrast, another nuclear Argonaute protein NRDE-3 appears to work solely in the somatic cells. Single-mutant animals hrde-1, nrde-1, $n r d e-2$, and nrde-4 all exhibit reduced viability of germ cells at elevated temperatures, indicating a crucial function mediated by nuclear RNAi in germline development [38].

Despite recent progress in identifying the genetic requirements for nuclear RNAi, its cellular functions in $C$. elegans remain elusive. Previous studies have shown that a large population of endo-siRNAs are loaded into the germline nuclear Argonaute protein HRDE-1 [38], suggesting that many regions of the genome can potentially be targeted by nuclear RNAi. In addition, mutations in $n$ rde-2 and nrde-4 lead to loss of H3K9 trimethylation in distinct loci [38]. While these studies clearly indicate important roles of nuclear RNAi in regulating chromatin structures, the global impact of nuclear RNAi on gene transcription has not been examined. Resolving this critical gap will identify the native targets of nuclear RNAi and delineate its endogenous functions in regulating gene expression and epigenetic response during animal development. To this end, we combined genetic, biochemical, and whole-genome computational approaches to identify and characterize transcriptional silencing events that are dependent on the germline nuclear Argonaute protein HRDE-1.

\section{Results and discussion}

The germline nuclear Argonaute protein HRDE-1 is required for the exclusion of RNA Polymerase II (Pol II) in a distinct set of genomic regions

To identify native targets of germline nuclear RNAi, we performed Pol II ChIP-seq using C. elegans wild-type populations and animals carrying a hrde-1 mutation. For this work, we used the hrde-1(tm1200) mutant allele, which has a 376-bp deletion in exon 3 and results in a premature stop codon before the essential PAZ and 
PIWI domains. This allele was also used in previous studies as a loss-of-function mutation [38,40,41]. To enrich for germline material, we used young adult hermaphrodites for both samples, in which germline contributes much of total chromatin content [43].

To minimize non-specific ChIP signal resulting from a single antibody, we used three different anti-Pol II C-terminal domain (CTD) YSPTSPS peptide antibodies, each corresponding to a different phosphorylation state of the peptide: unphosphorylated [8WG16], phosphorylated at the Ser2 residue [S2], and phosphorylated at the Ser5 residue [S5]. For this analysis, we constructed and sequenced a total of six Pol II ChIP-seq libraries, as well as two ChIP input libraries using the Illumina platform. An average of 2.1 million reads that perfectly aligned to the $C$. elegans genome were obtained (approximately $4 \times$ coverage).

Our assay was validated by the strong relative enrichment of Pol II ChIP signals at both the 5 ' and 3 ' ends of a set of "H3K4 di- or tri-methylation-anchored" genes, which represent actively transcribed genes in C. elegans [44] (Figure 1A). In each of the three Pol II ChIP-seq experiments (8WG16, S2, and S5), the averaged Pol II occupancy for the actively transcribed genes in the hrde-1 mutant showed only modest differences from the one in the wild type (modest decrease for 8WG16 and S5 and modest increase for $\mathrm{S} 2$ in the hrde-1 mutant). The differences were even smaller in a similar metagene analysis for all annotated protein-coding genes (data not shown).

To expand our analysis at a higher resolution for the entire genome, we divided the genome into 100,257 1kb segments and determined the Pol II ChIP-seq signal for each segment. Sequenced reads that were aligned to repetitive regions in the genome were normalized by the frequency that a non-unique read aligns to a different position in the genome. For most of the genome, the wild type and hrde-1 mutant exhibited similar levels of Pol II occupancy (Figure 1B). By using a 3-fold cutoff, the hrde-1 mutant animals showed consistent increases in Pol II occupancy at 191 1-kb regions in all three sets of Pol II ChIP samples (8WG16, S2, and S5) (Figure 1B and Additional file 1: Table S1). The median fold of increase in Pol II occupancy for these loci was 5.3 (8WG16), 5.8 (S2), and 9.0 (S5), indicating HRDE-1's prominent role in transcriptional silencing for at least $0.2 \%$ of the C. elegans genome. We provisionally refer to these 191 1-kb regions as the exemplary germline nuclear RNAi-dependent transcriptional silencing (GRTS) loci. Regions with a minimal 2-fold and 1.5-fold increase in the Pol II ChIP signals (hrde-1 vs. wild type) were listed in Additional file 1: Table S1. We found a much smaller number of 1-kb regions (15) which showed decreased levels of Pol II ChIP-seq signals in the hrde-1 mutant animals. Most of these changes were modest
(Figure 1B) and most likely corresponded to experimental noise or indirect effects of the hrde-1 mutation. They were not further analyzed in this work.

The genomic distribution of the GRTS loci is not random; many GRTS loci are in proximity to each other. By setting a proximity cutoff of $5 \mathrm{~kb}$, we found that 161 of the 191 exemplary GRTS loci (84.2\%) are clustered in 35 different regions, here after referred to as GRTS clusters (Figure 2C). Eight of these 35 clusters were at least $10 \mathrm{~kb}$, a size three times larger than the median size of C. elegans genes. In addition, all of the exemplary GRTS loci are located in five autosomes and strikingly absent in the sex chromosome (X) (Figure 2C). C. elegans has two sexes: hermaphrodite $(\mathrm{XX})$ and male $(\mathrm{X})$. Previous studies have shown that the entire $\mathrm{X}$ chromosome, with the exception of the left tip, is in a repressive chromatin state in C. elegans germ cells $[45,46]$. Therefore, the depletion of GRTS loci in the X chromosome may reflect a paradox in the nuclear RNAi field [24], which states that the target locus needs to be at least transiently transcribed in order to be targeted for transcriptional silencing. Alternatively, the $\mathrm{X}$ chromosome in C. elegans germ cells may lack certain DNA sequences or chromatin components that are necessary for nuclear RNAi.

\section{Germline nuclear RNAi-dependent heterochromatin (GRH) loci and transcriptional silencing (GRTS) loci are in proximity to each other}

We then asked to what extent the germline nuclear RNAidependent transcriptional silencing events are correlated with the heterochromatic responses on the native targets. In a previous study, we identified a set of nuclear RNAi-dependent heterochromatic regions (marked by H3K9 trimethylation) that are dependent on two different nuclear RNAi protein factors NRDE-2 and NRDE-4 [38]. To augment the previous study, we performed the H3K9me3 ChIP-seq analysis using the hrde-1(tm1200) mutant adult animals in this study. We found that the hrde-1 mutant had very similar $\mathrm{H} 3 \mathrm{~K} 9 \mathrm{me} 3$ defects to the nrde-2 and nrde-4 mutants. Using a 3-fold cutoff, we found that 215 out of the 358 NRDE-2/NRDE-4dependent $\mathrm{H} 3 \mathrm{~K} 9 \mathrm{me} 3$-enriched regions (60\%) were dependent on the HRDE-1 activity as well. We refer to these $2151-\mathrm{kb}$ regions as exemplary germline nuclear RNAi-dependent heterochromatic (GRH) loci (Figure 2A) (listed in Additional file 2: Table S2). Similarly to GRTS (listed in Additional file 3: Table S3), nearly all of the GRH regions are located in the five autosomes and only three 1 -kb GRH regions (1.4\%) were located in the X chromosome (Figure $2 \mathrm{C}$ ).

We compared the genomic distributions of the exemplary 215 GRH and 191 GRTS 1-kb loci and found that $35 \%$ of the GRH loci were within $10 \mathrm{~kb}$ distance of a GRTS locus (Figure $2 \mathrm{~B}$ and $2 \mathrm{C}$, p-values $<1 \times 10^{-12}$ ). Furthermore, 


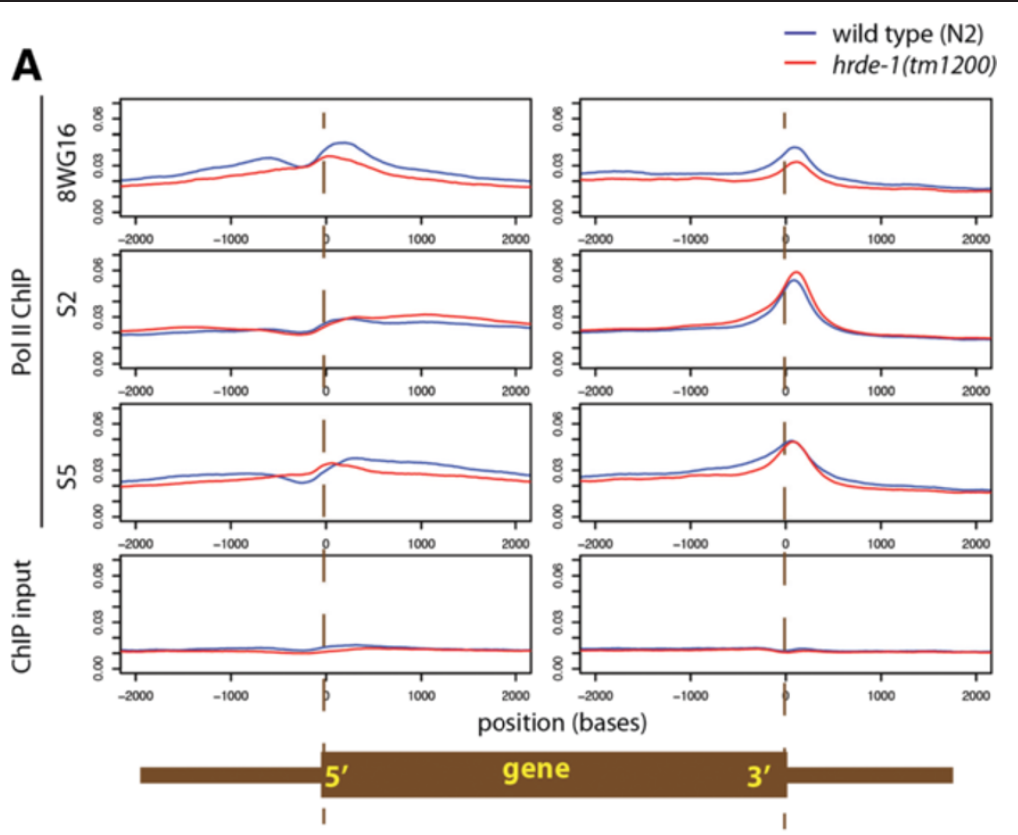

- $\Delta$ Pol II (hrde-1/wild type $>3$ ) for all three anti-Pol II antibodies (Germline nuclear RNAi-mediated transcriptional silenced [GRTS] loci)

- $\Delta$ Pol II (hrde-1/wild type $<1 / 3$ ) for all three anti-Pol II antibodies
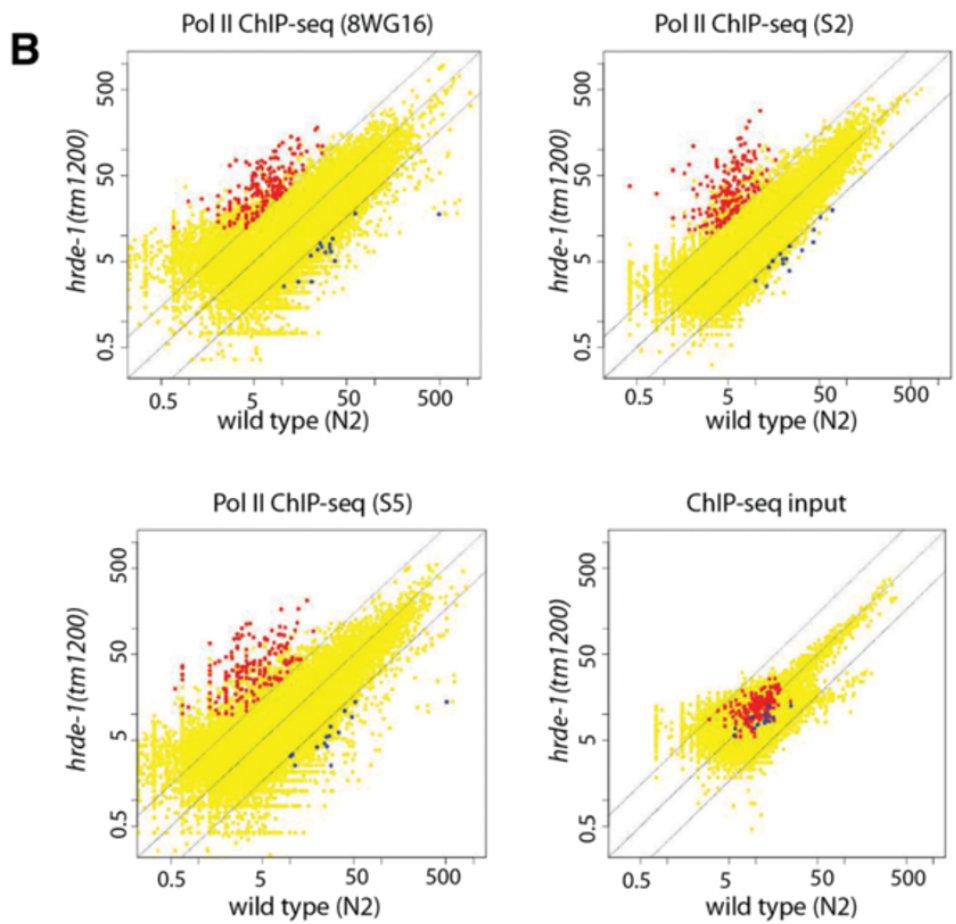

Figure 1 Loss of HRDE-1 increases RNA polymerase II (Pol II) occupancy at specific genomic loci. (A) Comparison of averaged Pol II occupancy levels in the wild type and hrde-1(tm1200) mutant animals around the 5' and 3' ends of 3903 "H3K4me2/3-anchored" genes [44]. Left panels: Pol II ChIP or ChIP input signal was plotted as a function of distance to the dyad of the "plus-one" nucleosome, defined by peak H3K4me2/3 nucleosomes near transcription start sites for the 3903 'H3K4me2/3-anchored' genes. Right panels: Pol II ChIP or ChIP input signal was plotted as a function of distance to the annotated ends of 3' UTR. (B) Pol II ChIP or ChIP input signals for the wild type and hrde-1(tm1200) mutant animals on 100,257 1-kb regions in the C. elegans genome. Each dot corresponds to a 1-kb region. Dotted lines indicate no-changes (the middle line) and three-fold differences (the flanking lines). 
A

- NRDE-2/NRDE-4-dependent H3K9m3-enriched loci $<1>$

- GRTS loci <2>

- overlap between $<1>$ and $<2>$

\section{H3K9me3 ChIP-seq}

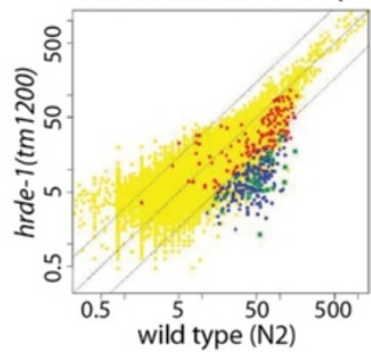

B
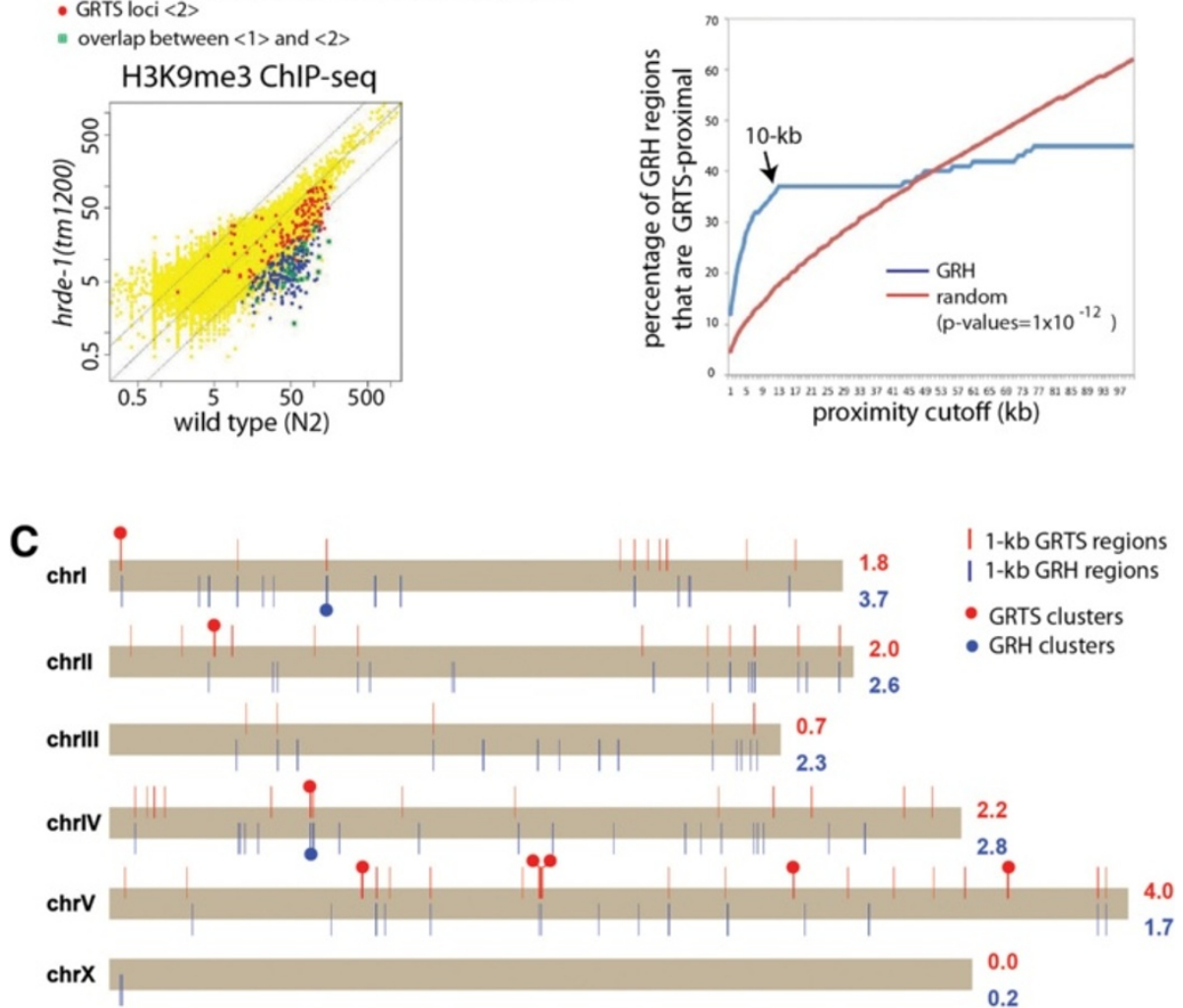

D germline nuclear RNAi-dependent heterochromatic (GRH) loci Pol II ChIP-seq (8WG16) Pol II ChIP-seq (S2)
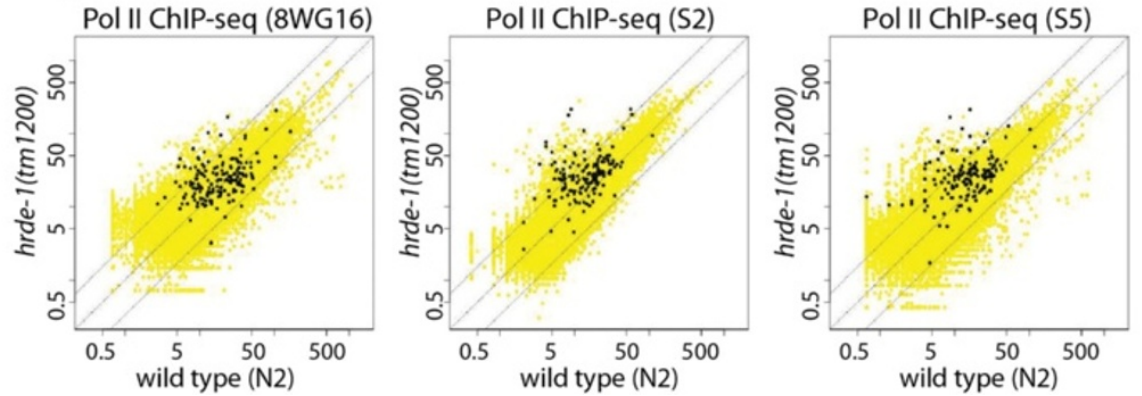

Figure 2 Germline nuclear RNAi-dependent heterochromatic (GRH) regions. (A) H3K9me3 ChIP-seg signals for the wild type (N2) and hrde-1 (tm1200) mutant on 100,257 1-kb regions in the C. elegans genome. GRH and GRTS loci were indicated by blue and red dots, respectively. (B) Blue curve: the percentage of the $2151-\mathrm{kb}$ GRH regions that are nearby to or overlap with any GRTS as a function of the proximity cutoff. Red curve: the minimal percentage to reject the null hypothesis that the $2151-\mathrm{kb}$ GRH regions have no tendency to overlap with or nearby to GRTS regions ( $p$-values $=1 \times 10^{-12}$, binomial distribution) as a function of the proximity cutoff. (C) Genomic distribution of GRTS (red bars) and GRH (blue bars) regions in each of the six chromosomes in C. elegans, with prominent GRTS clusters and GRH clusters (at least $10 \mathrm{~kb}$ ) indicated with solid circles. Numbers on the right of each chromosome are the percentages of the chromosome in GRTS (red) and GRH (blue) regions. (D) Scatter plots of the whole-genome Pol II ChIP-seq signals for the wild type and hrde-1(tm1200) mutant animals with the GRH regions highlighted (otherwise the same data as used in Figure 1B). Dotted lines (A and D) indicate no-changes (the middle line) and three-fold differences (the flanking lines).

approximately $50 \%$ of these GRH loci either overlapped with or were adjacent to a GRTS locus. These overlapping or proximally located GRTS and GRH loci represent a set of native targets at which germline nuclear RNAi triggers robust responses in both transcriptional silencing and H3K9 trimethylation. 
Intriguingly, many of the GRTS loci, at which the hrde-1 mutation leads to a dramatic transcriptional desilencing, had fewer H3K9me3 defects than the GRH loci (Figure 2A). In the hrde-1 mutant, the median fold-ofreduction of $\mathrm{H} 3 \mathrm{~K} 9 \mathrm{me} 3$ for GRH was 6.1, while the reduction for GRTS was only 2.5. Conversely, the hrde-1 mutation had a much weaker effect on Pol II exclusion in the GRH loci than the GRTS loci. The median foldsof-increase of Pol II for GRH loci were 1.3, 1.9, and 2.0 for 8 WG16, S2, and S5, respectively. In contrast, the increases for GRTS loci were 5.3, 5.8, and 9.0 for 8WG16, $\mathrm{S} 2$, and S5, respectively. In addition, many GRH loci exhibited no changes in Pol II occupancy between the wild type and hrde-1 mutant animals (Figure 2D). These results indicate that the responses of germline nuclear RNAi may differ among the native targets. Furthermore, these results ruled out a simple model in which the level of H3K9 methylation is the sole determinant of transcription silencing at the native targets of germline nuclear RNAi.

\section{Impact of germline nuclear RNAi on the primary transcriptome}

To further characterize the transcription activity, particularly its directionality, we decided to characterize pre-mRNA at the whole genome level. Previously, a nascent transcript sequencing method was developed to globally analyze pre-mRNA in Saccharomyces cerevisiae [47]. In this method, pre-mRNA was enriched by Pol II immunoprecipitation (IP) from DNase I-treated nuclear extract without crosslinking. We applied this method for C. elegans and found that $>99 \%$ of Pol II remained insoluble even after extensive DNase I treatment of the crude nuclear extract (data not shown). We subsequently learned from previous works that, in metazoans, the ternary complex of RNA polymerase II, DNA, and nascent RNA is resistant to high concentrations of detergents, chaotropes, salt, and polyanions $[48,49]$. So we modified the standard Pol II (S2) ChIP procedure and extracted RNA from the final IP product (see Methods for details), followed by RNA-seq analysis. We will refer to this method as premRNA-seq in this work.

To verify that pre-mRNA, not mRNA, was indeed enriched by this method, we searched for intronic sequences in the pre-mRNA-seq reads. We found that intronic reads were largely increased in the pre-mRNAseq samples when compared with the matching mRNAseq samples (Figure 3A). The [intron/exon] ratio of the pre-mRNA-seq was 19.3-fold higher than the ratio of the mRNA-seq for the wild type and 17.6-fold higher for the hrde-1 mutant. This verifies an efficient enrichment of primary transcripts by the pre-mRNA-seq method. We also observed regions with abundant pre-mRNA-seq reads but very low mRNA-seq reads (e.g., Figure 4B, comparing
pre-mRNA and mRNA for the hrde-1 mutant sample), evidencing a unique power of pre-mRNA-seq in revealing gene expression activity. In addition, pre-mRNA-seq compliments the Pol II ChIP-seq analysis by indicating the directionality of transcription activity.

We examined the pre-mRNA-seq signals from the wild type and hrde-1 mutant animals for all 1-kb segments throughout the genome (Figure 3B). Among the $191 \mathrm{ex}-$ emplary GRTS loci, $61.8 \%, 35.1 \%$, and $17.3 \%$ showed at least 10, 50, and 200-fold increase in pre-mRNA-seq signals in the hrde-1 mutant over the wild type animals (p-values $<0.0005$, Monte Carlo simulation), evidencing a large increase in nascent transcripts in the GRTS regions. Consistent with Pol II ChIP-seq analysis, pre-mRNA-seq analysis revealed a generally weaker transcription desilencing response in the GRH regions than in the GRTS regions. Among the 164 GRH loci, 25.6\%, 10.9\%, and 5.1\% of them showed 10,50, and 200-fold increases, respectively, in pre-mRNA-seq signals in the hrde-1 mutant compared to the wild type animals (p-values: 0.92, 0.72, and 0.002, Monte Carlo simulation). A weaker desilencing in the hrde-1 mutant in GRH regions was also evident from the mRNA-seq analysis (Figure 3C).

To test whether HRDE-1-dependent silencing events also require other nuclear RNAi pathway genes, we performed mRNA-seq analysis for mutants of three other core nuclear RNAi factors [nrde-2(gg91), nrde-3(gg66) and $n r d e-4(g g 129)]$. For the mRNA-seq analysis, we defined a set of exemplary HRDE-1 targets as the combined GRTS and GRH regions with increased mRNA-seq signals in hrde-1 mutant animals (a minimal of 3-fold increase in the hrde-1 mutant compared with the wild type mRNA-seq samples). We found that both the $n r d e-2 \mathrm{mu}-$ tant and the nrde-4 mutant showed strong de-silencing of the exemplary HRDE-1 target regions: $77.2 \%$ and $69.0 \%$ of the exemplary HRDE-1 targets showed at least 3-fold increases in mRNA-seq signals in the nrde-2 mutant and nrde-4 mutant, respectively, when compared with the wild type (Figure 3D and E). By contrast, only $22.3 \%$ of the exemplary HRDE-1 targets showed at least 3-fold increases in mRNA-seq signals in the nrde-3 mutant (Figure 3F). We previously found that the soma-specific nuclear Argonaute protein NRDE-3 is not required for the endogenous H3K9me3 responses mediated by NRDE-2 and NRDE-4 [38]. Taken together, these results further confirm that NRDE-3 has little or no function in germline nuclear RNAi.

\section{Germline nuclear RNAi primarily targets retrotransposons for transcriptional silencing}

To gain insight into the physiological role of germline nuclear RNAi in C. elegans, we examined the top sixteen largest GRTS clusters (5-19 kb) for their genomic annotations. Although protein-coding genes in these clusters 


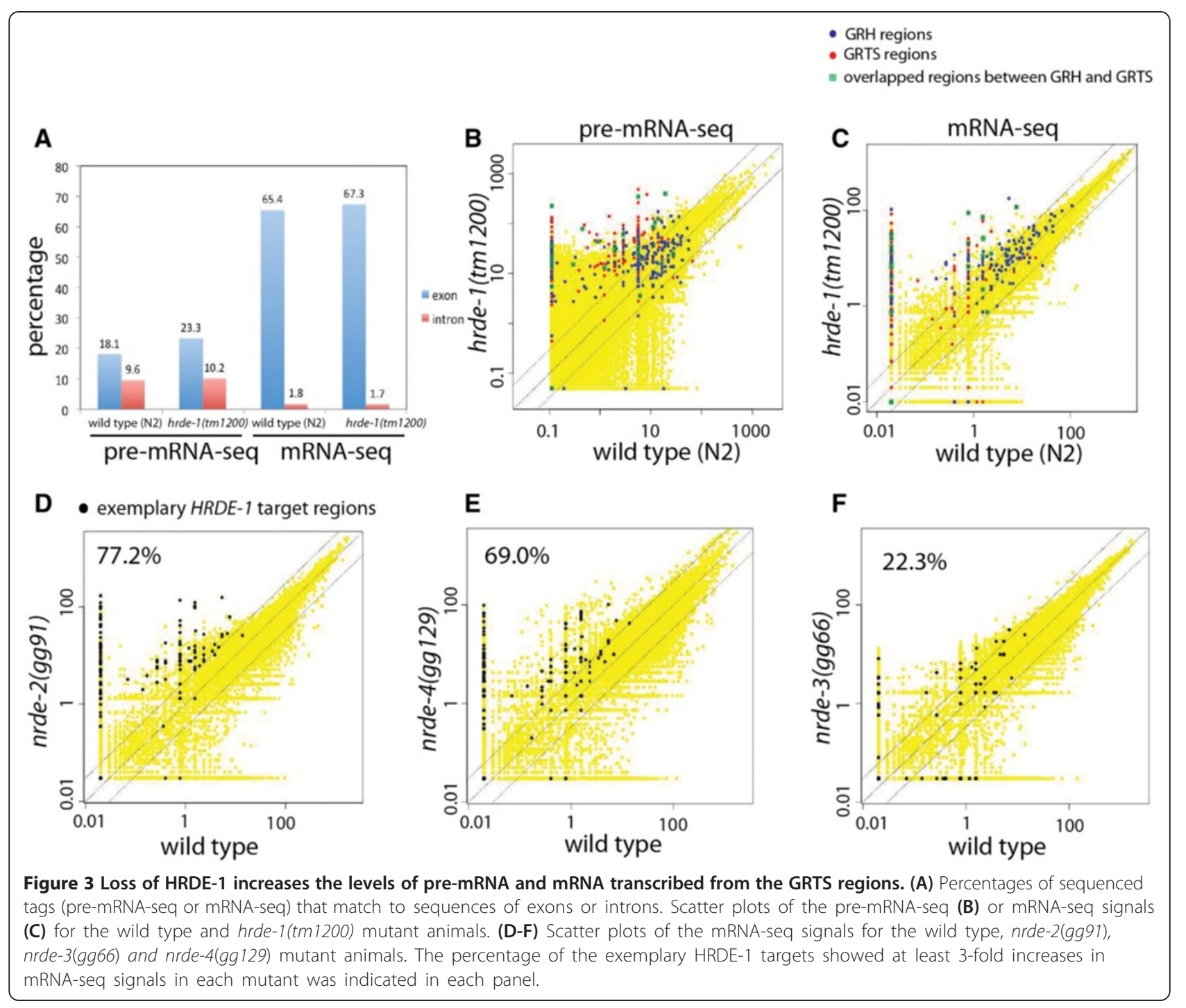

were not associated with any obvious common feature, we found that LTR retrotransposons were highly enriched in the GRTS clusters. 10 of these 16 GRTS clusters contain either full or partial LTR retrotransposon-type elements (p-value $=0.0005$, Monte Carlo simulation) (Table 1). This strong association was further evidenced by a close correspondence between the locations of target LTR retrotransposons and the local profiles of endo-siRNAs in both the wild type and hrde-1 mutant (see next section), H3K9me3 in the wild type, and Pol II occupancy/pre-mRNA in the hrde-1 mutant (two examples were shown in Figure 4A and $4 \mathrm{~B})$. We note that the top 16 largest GRTS clusters were used for this analysis because (1) full-length LTR retrotransposons in C. elegans are usually larger than $8 \mathrm{~kb}$ and (2) these larger clusters represent a highconfidence reference data set of HRDE-1 targets. Some of the smaller GRTS regions also contain retrotransposon fragments (data not shown). Within each of these LTR retrotransposons, nearly all of the pre-mRNA reads in the hrde-1 mutant sample were mapped to the sense strand of the protein-coding genes within the targets (e.g., Figure 4A and $4 \mathrm{~B})$. Together with profiles of Pol II-ChIP-seq and pre-mRNA-seq in the hrde-1 mutant, the strong transcription directionality strongly suggests that transcription of these LTR retrotransposons initiates from the upstream LTR (relative to the sense strand of protein-coding sequence within the transposons) and terminates within or near the downstream LTR.

In contrast to mammals and plants, retrotransposons in the C. elegans are sparse and occupy only approximately $0.4 \%$ of the genome [50-52]. Furthermore, retrotransposition in C. elegans has never been reported [52]. However, DNA transposons, which are active in transposition in C. elegans, occupy a much larger fraction (approximately 10\%) of the C. elegans genome [52]. We found that there was only one GRTS cluster that had 


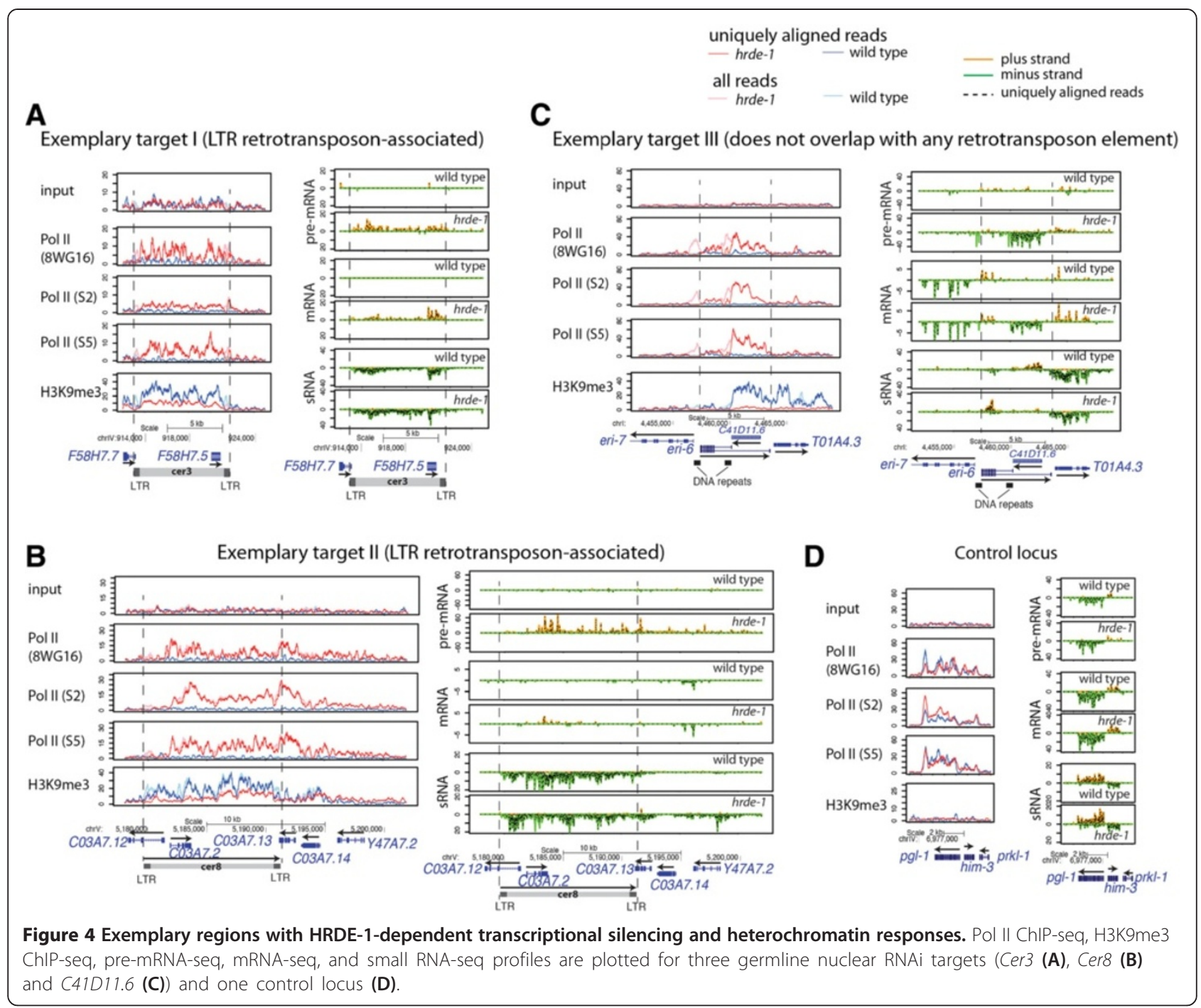

a DNA transposon (Tc1), which is embedded in an LTR retrotransposon in this case (Table 1). These results indicate that LTR retrotransposons, but not DNA transposons, are a major class of germline nuclear RNAi targets.

The native targets of germline nuclear RNAi are associated with abundant endo-siRNAs

To examine endo-siRNAs associated with native targets of germline nuclear RNAi, we performed small RNA sequencing analyses using wild-type adult animals and hrde-1 mutant adults. We used a 5'-mono-phosphate (mono-Pi)-independent method to capture small RNAs with mono-Pi or tri-Pi at their $5^{\prime}$ ends. As expected for RNAi-regulated loci, we found that the native target regions of germline nuclear RNAi were associated with abundant endo-siRNAs (Figures 4A-C and 5A). Small RNAs that were mapped to these regions measured predominantly 21 or 22 nucleotides long, began with a $G$ at the $5^{\prime}$ end (Figure 5B), and were antisense to the primary transcripts (Figure $4 \mathrm{~A}-\mathrm{C}$ ). These features indicate that these endo-siRNAs belong to the so-called 22G RNA family and are products of RdRPs $[9,10,53]$.

We also compared the endo-siRNA profiles between the wild type and hrde-1 mutants. The overall abundance of GRTS- or GRH-corresponding endo-siRNAs were similar between these two samples (Figure 5A). This result indicates that HRDE-1 does not directly function in the endo-siRNA biogenesis pathway. Nevertheless, some differences were observed between the wild type and the hrde-1 mutant when endo-siRNA profiles were examined in detail along the target sites. Possibly these differences correspond to a secondary effect of transcriptional de-silencing caused by the hrde-1 mutation.

\section{Non-retrotransposon GRTS regions}

In addition to LTR retrotransposons, we also identified several GRTS clusters that do not contain any annotated 
Table 1 Top sixteen largest germline nuclear RNAi-dependent transcriptional silencing (GRTS) clusters

\begin{tabular}{|c|c|c|c|c|c|c|c|}
\hline Genomic position (WS190) & $\begin{array}{l}\text { Length } \\
(\mathrm{kb})\end{array}$ & LTR retrotransposon & LINE & $\begin{array}{l}\text { Tc/mariner-type } \\
\text { DNA transposon }\end{array}$ & Other types of DNA repeat & Protein-coding genes & $\overline{\text { GRH }}$ \\
\hline chrl:226000-239000 & 13 & $\begin{array}{l}\text { A Cer13 fragment ( } 656 \mathrm{bp}) \text { with homology } \\
\text { to the PAO family retrotransposon integrase. } \\
\text { No LTR at this target. }\end{array}$ & - & - & & $\begin{array}{l}\text { Y48G1BM.5, Y48G1BM.6, } \\
\text { Y48G1BM.7 }\end{array}$ & + \\
\hline chrl:4456000-4464000 & 8 & - & - & - & $\begin{array}{l}\text { Two 930 bp DNA repeats that are } 1.9 \mathrm{~kb} \text { apart and 99\% i } \\
\text { dentical (chrl:4456382-4457314 and chrl:4459215-4460136). } \\
\text { One of the two repeats is located between eri-6 and eri-7 } \\
\text { and contains the promoter active for the two genes. }\end{array}$ & $\begin{array}{l}\text { eri-7, eri-6, C41D11.6, } \\
\text { T01A4.3 }\end{array}$ & + \\
\hline chrl:11438000-11449000 & 11 & Cer16-2 (9.3 kb) with LTR in both ends & - & - & & C27C7.1 & + \\
\hline chrll:2150000-2163000 & 13 & Cer9-1 (9.5 kb) with LTR in both ends & - & - & & C40A11.8, math-18 & + \\
\hline chrll:2516000-2521000 & 5 & - & - & - & $\begin{array}{l}\text { Two 430 bp DNA repeats that are } 3.5 \mathrm{~kb} \text { apart and } 98 \% \\
\text { identical to each other (chrll:2,520,235-2,520,670 and } \\
\text { chrll:2516272-2516702) }\end{array}$ & bath-12, bath-13 & + \\
\hline chrll:13245000-13250000 & 5 & - & - & - & & F15D4.5, F15D4.6 & + \\
\hline chrlV:915000-922000 & 7 & $\begin{array}{l}\text { An extensive Cer3-1 ( } 8.7 \mathrm{~kb}) \text { with LTR in } \\
\text { both ends }\end{array}$ & - & - & & F58H7.5, F58H7.6 & + \\
\hline chrlv:4124000-4138000 & 14 & $\begin{array}{l}\text { A solo LTR (Cer2) with four other Cer2 } \\
\text { fragments ( } 275 \mathrm{bp}-412 \mathrm{bp} \text { ) }\end{array}$ & - & - & & F49F1.7, F49F1.8 & + \\
\hline chrlV:13633000-13639000 & 6 & - & $\begin{array}{l}\text { LINE2C1 } \\
\text { fragment }\end{array}$ & - & & C08F11.5, C08F11.7 & + \\
\hline chrV:5182000-5201000 & 19 & Cerg-1 (11.5 kb) with LTR in both ends & - & - & & $\begin{array}{l}\text { C03A7.12, CO3A7.2, } \\
\text { C03A7.13, abu-8, Y47A7.2 }\end{array}$ & + \\
\hline chrV:5482000-5487000 & 5 & - & - & - & & srg-66, srg-65, grl-18 & + \\
\hline chrV:8826000-8837000 & 11 & $\begin{array}{l}\text { Mixed Cer8 and Cer9 sequence (19.8 kb) } \\
\text { with LTR (cer9) in both ends, }\end{array}$ & - & - & & $\begin{array}{l}\text { F09B7.3, W09B7.2 (F07B7.2), } \\
\text { W09B7.1 (F07B7.1), F07B7.7, } \\
\text { F07B7.8 }\end{array}$ & + \\
\hline $\begin{array}{l}\text { chrV:8868000-8879000 } \\
\text { (identical sequence to } \\
\text { chrV:8826000-8837000) }\end{array}$ & 11 & $\begin{array}{l}\text { Mixed Cer8 and Cer9 sequence (19.8 kb) } \\
\text { with LTR (cer9) in both ends, }\end{array}$ & - & - & & $\begin{array}{l}\text { F09B7.3, W09B7.2 (F07B7.2), } \\
\text { W09B7.1 (F07B7.1), F07B7.7, } \\
\text { F07B7.8 }\end{array}$ & + \\
\hline chrV:14039000-14055000 & 16 & - & LINE2H & & & $\begin{array}{l}\text { T08G5.9, T08G5.8, T08G5.7, } \\
\text { F58D12.5, T08G5.19 }\end{array}$ & \\
\hline chrV:17568000-17573000 & 5 & A Cer8-1 fragment (68 bp) & - & - & & C38D9.2 & + \\
\hline chrV:18439000-18457000 & 18 & Cer8-1 (19.4 kb) with LTR in both ends & - & $\begin{array}{l}\text { Tc1 embedded } \\
\text { in the Cer8-1 }\end{array}$ & & $\begin{array}{l}\text { ZK262.8, ZK262.9, ZK228.1, } \\
\text { ZK228.10 }\end{array}$ & + \\
\hline
\end{tabular}


- GRH regions

- GRTS regions

A = overlapped regions between GRH and GRTS

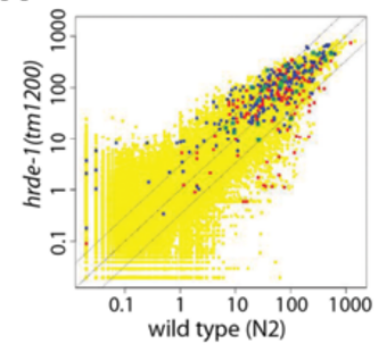

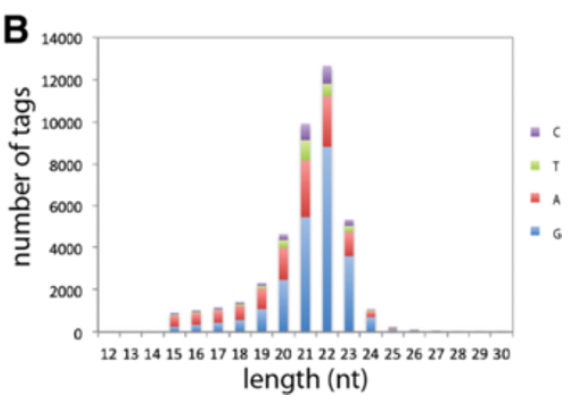

Figure 5 HRDE-1 is not required for the biogenesis of germline nuclear RNAi-associated endo-siRNA. (A) Scatter plots of the small RNA-seq signals for the wild type and hrde-1(tm1200) mutant animals. Each dot represents each of the 100,257 1-kb regions, with GRTS, GRH, and overlapped regions between GRTS and GRH highlighted. Dotted lines indicate no-changes (the middle line) and three-fold differences (the flanking lines). (B) The size distribution and nucleotide distribution for the first position at the 5' end of small RNAs in the GRTS and GRH regions.

retrotransposons. One prominent example covers the C41D11.6 gene (Figure 4C), which exhibits strong increases in Pol II occupancy, pre-mRNA levels, and mRNA levels in the hrde-1 mutant animals. C41D11.6 also exhibits a high degree of HRDE-1-dependent H3K9 trimethylation, which extends into a neighboring, divergently transcribed gene (T01A4.3). These two genes appear to be nematode-specific genes with unknown functions.

On the other side of C41D11.6 is a locus encoding the eri-6 and eri-7 genes (Figure 4C). Despite the divergent transcription of eri-6/eri-7, their mRNAs are joined together by an unusual trans-splicing event [54]. Intriguingly, by performing qRT-PCR using primers specific to the eri-6/7 trans-spliced product, we observed a $50 \%$ reduction in the eri-6/7 mRNA level in the hrde-1 mutant, suggesting the existence of a local effect of germline nuclear RNAi on the expression of a neighboring gene. We found that loss of eri-6/7 had no silencing defects on the natural targets of germline nuclear RNAi [data not shown].

\section{The piRNA pathway is not required for germline nuclear RNAi responses at the native targets}

The piRNA pathway in C. elegans plays an important role in silencing certain pseudogenes, DNA transposons, and other types of foreign DNA such as transgenes in the germline [55-59]. The broad targeting capability comes from the highly diverse repertoire of sequences encoded by piRNAs (also called 21U RNAs) in C. elegans. piRNAmediated silencing of transgenes was previously shown to be dependent on HRDE-1 [40,41].

To investigate whether the piRNA pathway is required for germline nuclear RNAi activity on the native targets, we performed genome-wide analyses using a piRNA pathway mutant. The $C$. elegans genome encodes two PIWI family proteins, PRG-1 and PRG-2. Previous studies found that PRG-1 is required for the stability of piRNAs and essential for piRNA activity. By contrast, PRG-2 has very little or no function in the piRNA pathway $[11,56,60]$. Previous studies found that a subset of the endogenous $22 \mathrm{G}$ RNA population is dependent on the piRNA pathway $[57,58]$. To ask whether regions with PRG-1-dependent endo-siRNAs overlap with the exemplary GRH and GRTS regions, we examined two sets of published small RNAseq data for the prg-1(n4357) mutant and matching wild type animals [58,61]. By using a 3-fold cutoff, we found that only $7.5 \%$ and $20.6 \%$ of the exemplary GRTS and GRH regions, respectively, had reduced levels of endosiRNAs in the prg-1 mutants. The reduction for most of these regions was modest (Figure 6A). These results indicate that endo-siRNA levels for the majority of the natural targets of germline nuclear RNAi are not dependent on the piRNA pathway.

We then asked whether loss of prg-1 had any effect on the germline nuclear RNAi-mediated heterochromatin response and transcriptional silencing at the native target sites. For this we performed H3K9me3 and Pol II (S2) ChIP-seq experiments using the prg-1(n4357) mutant animals. The results showed that loss of PRG-1 had virtually no effect on the H3K9me3 or Pol II occupancy profiles on the native targets of germline nuclear RNAi (Figure 6B and C), indicating that germline nuclear RNAi in C. elegans does not require the piRNA pathway.

\section{Conclusions}

\section{Retrotransposon silencing}

By taking a combined genetic, biochemical, and computational approach, we identified a distinct set of genomic regions that are naturally targeted by germline nuclear RNAi for transcriptional silencing and/or heterochromatin formation in $C$. elegans. The enrichment of retrotransposon elements in these regions suggests that germline nuclear RNAi evolved as a genome defense mechanism 


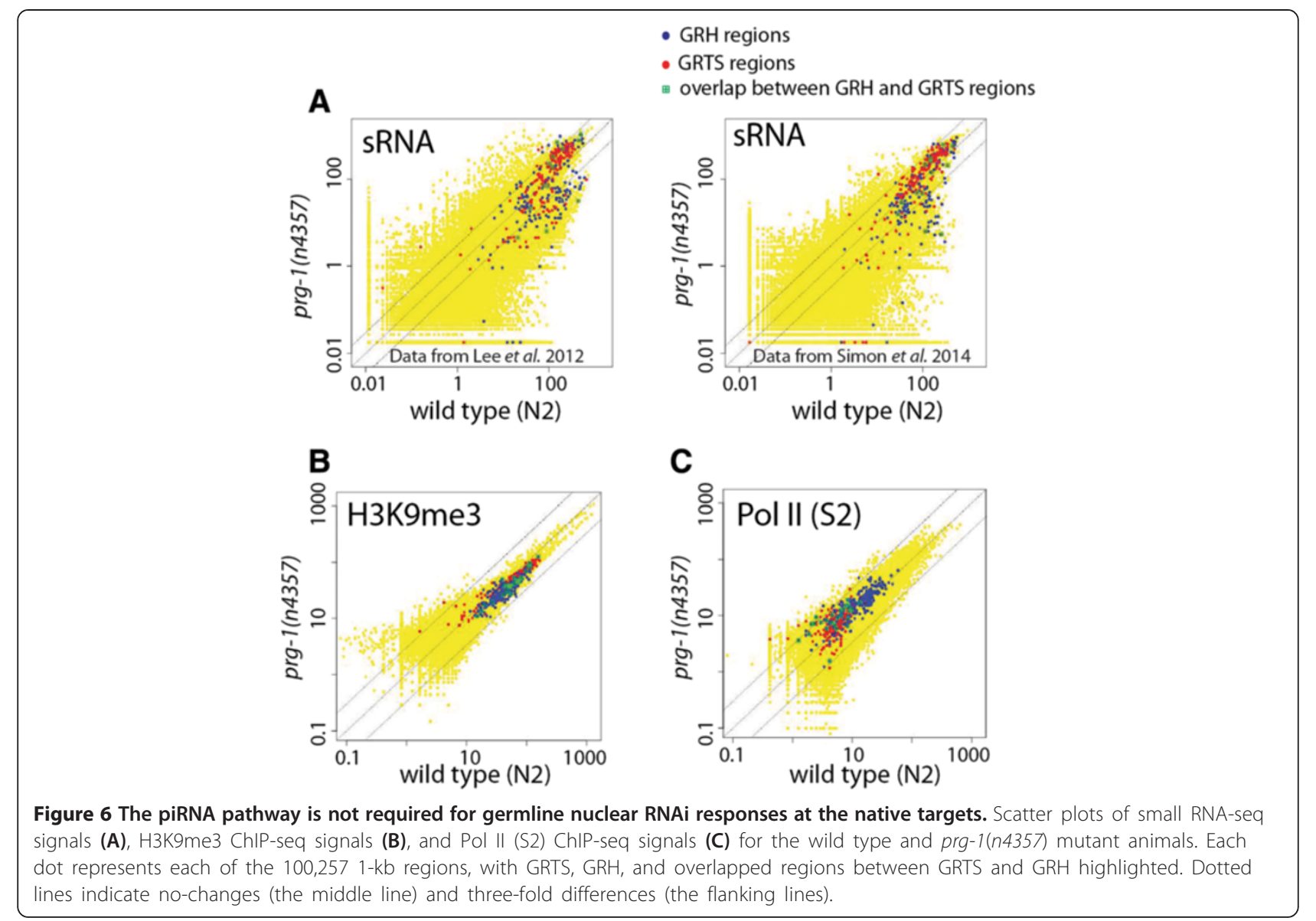

against this type of mobile DNA. Our detailed wholegenome profiling of Pol II occupancy and pre-mRNA indicates that, first, the HRDE-1-targeted retrotransposons in C. elegans are intrinsically active in transcription. Second, germline nuclear RNAi-mediated transcriptional silencing at these regions occurs prior to (or at) the formation of the transcriptional preinitiation complex. Taken together, these findings indicate that one function of germline nuclear RNAi is to silence the retrotransposons in the C. elegans genome.

\section{piRNA}

Studies using Drosophila, zebrafish, and mice have revealed that the piRNA pathway plays a central role in silencing retrotransposons at both the transcriptional and post-transcriptional levels. piRNAs in C. elegans (also called 21U RNA) have been shown to silence Tc3 (a mariner-type DNA transposon), certain pseudogenes, and transgenes in the germline [56-58]. Previous studies indicated that HRDE-1 is required for the silencing of piRNA-targeted reporter genes $[40,41]$. In this study, we showed that the piRNA pathway in C. elegans is not required for germline nuclear RNAi activity at LTR retrotransposons. These findings suggest that the HRDE-1-mediated nuclear RNAi and the piRNA pathway evolved to have distinct target specificity in genome surveillance.

\section{Triggers of nuclear RNAi}

The triggering mechanisms that initiate RNAi-mediated transcriptional silencing appear to be quite diverse in different organisms. In plants, nuclear RNAi can be triggered in trans by dsRNA produced from an infecting virus or transgene [62,63]. Cryptic splicing, aberrant transcription products, and transcription-blocking activities (such as DNA replication) have been shown to play important roles in triggering RNAi-mediated chromatin silencing in cis in fission yeast [64-66].

The native targets of germline nuclear RNAi in C. elegans identified in this study often contain DNA repeats that are associated with promoter activities (e.g., LTRs). It is possible that certain unusual nucleic acid interactions (RNA-RNA, RNA-DNA, or DNA-DNA) associated with transcriptionally active DNA repeats are recognized by the host as signals for unwanted genetic elements. In the case of the eri-6/eri-7 locus, although no DNA transposon or retrotransposon can be found nearby, there are several unusual features of gene structures: (1) an approximately $0.9 \mathrm{~kb}$ DNA sequence that includes the promoters 
for eri-6 and eri-7 is duplicated $3 \mathrm{~kb}$ away in the same orientation (Figure 4C), which resembles of LTRs; (2) the partially overlapped genes C41D11.6 and eri-6 are transcribed in convergent directions; (3) and the C41D11.6 gene is an intron-less gene. We are currently investigating whether nuclear RNAi at this region is caused by any of these features.

A previous study found that at least one of the LTR retrotransposons, namely Cer1, is actively transcribed in germ cells of wild type C. elegans [67]. We observed the active expression of Cer 1 in the wild type in our data set as well (data not shown). This suggests that DNA repeats, such as LTR, may not be sufficient to trigger silencing. Other genetic activities or molecular structures that are intrinsic to retrotransposons may be required as well. Alternatively, the triggering mechanism may involve interference between genetic activities (e.g., transcription and DNA replication) that originates from foreign DNA and neighboring host genes. Such interference may be absent in the Cer1 locus. We consider these models to be valid hypotheses for further study.

\section{Absence of response in the $\mathrm{X}$ chromosome}

With a few exceptions, GRTS and GRH regions are situated in all five autosomes but not on the X chromosome. What are the possibly explanations for their absence in the $\mathrm{X}$ chromosome? Our previous study showed that abundant small RNAs from both types of chromosomes are associated with HRDE-1 [38]. Therefore, this positioning cannot be due to the lack of X-chromosome endosiRNAs. LTR retrotransposons themselves are not absent in the X chromosome either. Some of the X-located LTR elements are nearly identical to ones located in the GRTS regions. At this point we cannot rule out the lack of certain intrinsic triggering sequences in the X-located LTR retrotransposons. It is also possible that the lack of X-located GRTS or GRH regions is due to the global silencing of the $\mathrm{X}$ chromosome in the germ cells of C. elegans. Previous studies found that the entire $\mathrm{X}$ chromosome in C. elegans germ cells, with the exception of one tip of the $\mathrm{X}$ chromosome, is in a repressive chromatin state $[45,46]$. It is conceivable that a brief period of transcription is needed to provide nascent transcripts as binding sites for targeting siRNA-associated silencing complex. Transient transcription may even be required to generate the triggering signals, for example, by providing nascent transcripts recognized as improperly spliced or terminated transcripts, or providing nascent transcripts as templates or substrates for siRNA biogenesis.

\section{Methods}

\section{Worm strains}

C. elegans strain N2 was used as the standard wild-type strain. Mutant alleles used in this study were hrde-1 (tm1200) [38,40,41], nrde-2(gg91) [36], nrde-3(gg66) [35], nrde-4(gg129) [37] and prg-1(n4357) [56]. Synchronized animals were cultured on NGM plates at $19^{\circ} \mathrm{C}$ and fed on E. coli OP50 [68].

Chromatin Immunoprecipitation (ChIP)-seq, pre-mRNAseq, mRNA-seq, and small RNA-seq procedures are described in Additional file 4.

\section{Availability of supporting data}

All sequencing data used in this study have been deposited in GEO (Accession Number: GSE58031).

\section{Additional files}

Additional file 1: Table S1. GRTS and GRH regions identified with cutoffs of 1.5, 2, or 3-fold differences.

Additional file 2: Table S2. GRH clusters identified using data from Additional file 1: Table S1. Each of these regions has at least one 1-kb region with a minimal 3 -fold decrease in $\mathrm{H} 3 \mathrm{~K} 9 \mathrm{me} 3$ in all three nuclear RNAi mutants (nrde-2, nrde-4, and hrde-1) and also includes nearby regions with at least 1.5-fold decreases. Each cluster was indicated whether it overlaps with any GRTS cluster. Genes in each GRH cluster were listed.

Additional file 3: Table S3. GRTS clusters identified using data from Additional file 1: Table S1. Each of these regions has at least one 1-kb region with a minimal 3 -fold increase in Pol II ChIP-seq signal in hrde-1 and also includes nearby regions with at least 1.5 -fold increases. Each cluster was indicated whether it overlaps with any GRH cluster. Genes in each GRTS cluster were listed.

Additional file 4: Supplementary Methods.

\section{Abbreviations}

GRTS: Germline nuclear RNAi-dependent transcriptional silencing; GRH: Germline nuclear RNAi-dependent heterochromatin.

\section{Competing interests}

The authors declare that they have no competing interests.

\section{Authors' contributions}

JN and SG designed the experiments. JN and EC collected the samples and performed all the experiments. JN and SG performed data analysis and wrote the manuscripts. All authors read and approved the final manuscript.

\section{Acknowledgments}

We thank Natallia Kalinava, Alex Huang, Thi Trinh, Olivia Kan, Elaine Gavin, Shobhna Patel and Monica Driscoll for help, suggestions and support. Research reported in this publication was supported by the Busch Biomedical Grant and the National Institute of General Medical Sciences of the National Institutes of Health under award number R01GM111752. Some strains were provided by the CGC, which is funded by NIH Office of Research Infrastructure Programs (P40 OD010440). The content is solely the responsibility of the authors and does not necessarily represent the official views of the National Institutes of Health.

Received: 26 June 2014 Accepted: 10 December 2014

Published: 22 December 2014

\section{References}

1. Fire A, Xu S, Montgomery MK, Kostas SA, Driver SE, Mello CC: Potent and specific genetic interference by double-stranded RNA in Caenorhabditis elegans. Nature 1998, 391(6669):806-811.

2. Kennerdell JR, Carthew RW: Use of dsRNA-mediated genetic interference to demonstrate that frizzled and frizzled 2 act in the wingless pathway. Cell 1998, 95(7):1017-1026.

3. Bernstein E, Caudy AA, Hammond SM, Hannon GJ: Role for a bidentate ribonuclease in the initiation step of RNA interference. Nature 2001, 409(6818):363-366. 
4. Hammond SM, Boettcher S, Caudy AA, Kobayashi R, Hannon GJ: Argonaute2, a link between genetic and biochemical analyses of RNAi. Science 2001, 293(5532):1146-1150

5. Tuschl T, Zamore PD, Lehmann R, Bartel DP, Sharp PA: Targeted mRNA degradation by double-stranded RNA in vitro. Genes Dev 1999, 13(24):3191-3197.

6. Hammond SM, Bernstein E, Beach D, Hannon GJ: An RNA-directed nuclease mediates post-transcriptional gene silencing in Drosophila cells. Nature 2000, 404(6775):293-296.

7. Elbashir SM, Lendeckel W, Tuschl T: RNA interference is mediated by 21- and 22-nucleotide RNAs. Genes Dev 2001, 15(2):188-200.

8. Motamedi MR, Verdel A, Colmenares SU, Gerber SA, Gygi SP, Moazed D: Two RNAi complexes, RITS and RDRC, physically interact and localize to noncoding centromeric RNAs. Cell 2004, 119(6):789-802.

9. Pak J, Fire A: Distinct populations of primary and secondary effectors during RNAi in C. elegans. Science 2007, 315(5809):241-244.

10. Sijen $\mathrm{T}$, Steiner $F A$, Thijssen $\mathrm{KL}$, Plasterk RH: Secondary siRNAs result from unprimed RNA synthesis and form a distinct class. Science 2007, 315(5809):244-247.

11. Batista PJ, Ruby JG, Claycomb JM, Chiang R, Fahlgren N, Kasschau KD, Chaves DA, Gu W, Vasale JJ, Duan S, Conte D Jr, Luo S, Schroth GP, Carrington JC, Bartel DP, Mello CC: PRG-1 and 21U-RNAs interact to form the piRNA complex required for fertility in C. elegans. Mol Cell 2008, 31(1):67-78.

12. Claycomb JM, Batista PJ, Pang KM, Gu W, Vasale JJ, van Wolfswinkel JC, Chaves DA, Shirayama M, Mitani S, Ketting RF, Conte D Jr, Mello CC: The Argonaute CSR-1 and its 22G-RNA cofactors are required for holocentric chromosome segregation. Cell 2009, 139(1):123-134.

13. Saito K, Siomi MC: Small RNA-mediated quiescence of transposable elements in animals. Dev Cell 2009, 19(5):687-697.

14. Gent Jl, Lamm AT, Pavelec DM, Maniar JM, Parameswaran P, Tao L, Kennedy S, Fire AZ: Distinct phases of siRNA synthesis in an endogenous RNAi pathway in C. elegans soma. Mol Cell 2010, 37(5):679-689.

15. Maniar JM, Fire AZ: EGO-1, a C. elegans RdRP, modulates gene expression via production of mRNA-templated short antisense RNAs. Curr Biol 2011 21(6):449-459.

16. Juang BT, Gu C, Starnes L, Palladino F, Goga A, Kennedy S, L'Etoile ND: Endogenous nuclear RNAi mediates behavioral adaptation to odor. Cell 2013, 154(5):1010-1022.

17. Seth M, Shirayama M, Gu W, Ishidate T, Conte D Jr, Mello CC: The C. elegans CSR-1 argonaute pathway counteracts epigenetic silencing to promote germline gene expression. Dev Cell 2013, 27(6):656-663.

18. Wedeles CJ, Wu MZ, Claycomb JM: Protection of germline gene expression by the C. elegans Argonaute CSR-1. Dev Cell 2013, 27(6):664-671

19. Billi AC, Fischer SE, Kim JK: Endogenous RNAi pathways in C. elegans. WormBook 2014, 1-49.

20. Wassenegger M: RNA-directed DNA methylation. Plant Mol Biol 2000, 43(2-3):203-220.

21. Herr AJ, Baulcombe DC: RNA silencing pathways in plants. Cold Spring Harb Symp Quant Biol 2004, 69:363-370.

22. Moazed D: Small RNAs in transcriptional gene silencing and genome defence. Nature 2009, 457(7228):413-420.

23. Grewal SI: RNAi-dependent formation of heterochromatin and its diverse functions. Curr Opin Genet Dev 2010, 20(2):134-141.

24. Castel SE, Martienssen RA: RNA interference in the nucleus: roles for small RNAs in transcription, epigenetics and beyond. Nat Rev Genet 2013, 14(2):100-112.

25. Brennecke J, Aravin AA, Stark A, Dus M, Kellis M, Sachidanandam R, Hannon GJ: Discrete small RNA-generating loci as master regulators of transposon activity in Drosophila. Cell 2007, 128(6):1089-1103.

26. Gunawardane LS, Saito K, Nishida KM, Miyoshi K, Kawamura Y, Nagami T, Siomi H, Siomi MC: A slicer-mediated mechanism for repeat-associated siRNA 5' end formation in Drosophila. Science 2007, 315(5818):1587-1590.

27. Sienski G, Donertas D, Brennecke J: Transcriptional silencing of transposons by Piwi and maelstrom and its impact on chromatin state and gene expression. Cell 2012, 151(5):964-980.

28. Le Thomas A, Rogers AK, Webster A, Marinov GK, Liao SE, Perkins EM, Hur JK, Aravin AA, Toth KF: Piwi induces piRNA-guided transcriptional silencing and establishment of a repressive chromatin state. Genes Dev 2013, 27(4):390-399.
29. Rozhkov NV, Hammell M, Hannon GJ: Multiple roles for Piwi in silencing Drosophila transposons. Genes Dev 2013, 27(4):400-412.

30. Montgomery MK, Xu S, Fire A: RNA as a target of double-stranded RNA-mediated genetic interference in Caenorhabditis elegans. Proc Natl Acad Sci U S A 1998, 95(26):15502-15507.

31. Bannister AJ, Zegerman P, Partridge JF, Miska EA, Thomas JO, Allshire RC, Kouzarides T: Selective recognition of methylated lysine 9 on histone $\mathrm{H} 3$ by the HP1 chromo domain. Nature 2001, 410(6824):120-124.

32. Schotta G, Ebert A, Krauss V, Fischer A, Hoffmann J, Rea S, Jenuwein T, Dorn R, Reuter G: Central role of Drosophila SU(VAR)3-9 in histone H3-K9 methylation and heterochromatic gene silencing. EMBO J 2002, 21(5):1121-1131.

33. Peters AH, Kubicek S, Mechtler K, O'Sullivan RJ, Derijck AA, Perez-Burgos L, Kohlmaier A, Opravil S, Tachibana M, Shinkai Y, Martens JH, Jenuwein T: Partitioning and plasticity of repressive histone methylation states in mammalian chromatin. Mol Cell 2003, 12(6):1577-1589.

34. Malone CD, Anderson AM, Motl JA, Rexer CH, Chalker DL: Germ line transcripts are processed by a Dicer-like protein that is essential for developmentally programmed genome rearrangements of Tetrahymena thermophila. Mol Cell Biol 2005, 25(20):9151-9164.

35. Guang S, Bochner AF, Pavelec DM, Burkhart KB, Harding S, Lachowiec J, Kennedy S: An Argonaute transports siRNAs from the cytoplasm to the nucleus. Science 2008, 321(5888):537-541.

36. Guang S, Bochner AF, Burkhart KB, Burton N, Pavelec DM, Kennedy S: Small regulatory RNAs inhibit RNA polymerase II during the elongation phase of transcription. Nature 2010, 465(7301):1097-1101.

37. Burkhart KB, Guang S, Buckley BA, Wong L, Bochner AF, Kennedy S: A pre-mRNA-associating factor links endogenous siRNAs to chromatin regulation. PLOS Genet 2011, 7(8):e1002249.

38. Buckley BA, Burkhart KB, Gu SG, Spracklin G, Kershner A, Fritz H, Kimble J, Fire A, Kennedy S: A nuclear Argonaute promotes multigenerational epigenetic inheritance and germline immortality. Nature 2012, 489(7416):447-451.

39. Gu SG, Pak J, Guang S, Maniar JM, Kennedy S, Fire A: Amplification of siRNA in Caenorhabditis elegans generates a transgenerational sequence-targeted histone $\mathrm{H} 3$ lysine 9 methylation footprint. Nat Genet 2012, 44(2):157-164.

40. Ashe A, Sapetschnig A, Weick EM, Mitchell J, Bagijn MP, Cording AC, Doebley AL, Goldstein LD, Lehrbach NJ, Le Pen J, Pintacuda G, Sakaguchi A, Sarkies $P$, Ahmed S, Miska EA: piRNAs can trigger a multigenerational epigenetic memory in the germline of C. elegans. Cell 2012, 150(1):88-99.

41. Shirayama M, Seth M, Lee HC, Gu W, Ishidate T, Conte D Jr, Mello CC: piRNAs initiate an epigenetic memory of nonself RNA in the $C$. elegans germline. Cell 2012, 150(1):65-77.

42. Yigit E, Batista PJ, Bei Y, Pang KM, Chen CC, Tolia NH, Joshua-Tor L, Mitani S, Simard MJ, Mello CC: Analysis of the C. elegans Argonaute family reveals that distinct Argonautes act sequentially during RNAi. Cell 2006, 127(4):747-757.

43. Hirsh D, Oppenheim D, Klass M: Development of the reproductive system of Caenorhabditis elegans. Dev Biol 1976, 49(1):200-219.

44. Gu SG, Fire A: Partitioning the C. elegans genome by nucleosome modification, occupancy, and positioning. Chromosoma 2010, 119(1):73-87.

45. Reinke V, Smith HE, Nance J, Wang J, Van Doren C, Begley R, Jones SJ, Davis EB, Scherer S, Ward S, Kim SK: A global profile of germline gene expression in C. elegans. Mol Cell 2000, 6(3):605-616.

46. Kelly WG, Schaner CE, Dernburg AF, Lee MH, Kim SK, Villeneuve AM, Reinke V: $\mathrm{X}$-chromosome silencing in the germline of C. elegans. Development 2002, 129(2):479-492.

47. Churchman LS, Weissman JS: Nascent transcript sequencing visualizes transcription at nucleotide resolution. Nature 2011, 469(7330):368-373.

48. Cai H, Luse DS: Transcription initiation by RNA polymerase II in vitro. Properties of preinitiation, initiation, and elongation complexes. J Biol Chem 1987, 262(1):298-304.

49. Wuarin J, Schibler U: Physical isolation of nascent RNA chains transcribed by RNA polymerase II: evidence for cotranscriptional splicing. Mol Cell Biol 1994, 14(11):7219-7225.

50. Bowen NJ, McDonald JF: Genomic analysis of Caenorhabditis elegans reveals ancient families of retroviral-like elements. Genome Res 1999, 9(10):924-935. 
51. Ganko EW, Fielman KT, McDonald JF: Evolutionary history of Cer elements and their impact on the C. elegans genome. Genome Res 2001, 11(12):2066-2074.

52. Bessereau JL: Transposons in C. elegans. WormBook 2006, 1-13.

53. Gu W, Shirayama M, Conte D Jr, Vasale J, Batista PJ, Claycomb JM, Moresco JJ, Youngman EM, Keys J, Stoltz MJ, Chen CC, Chaves DA, Duan S, Kasschau KD, Fahlgren N, Yates JR 3rd, Mitani S, Carrington JC, Mello CC: Distinct argonaute-mediated 22G-RNA pathways direct genome surveillance in the C. elegans germline. Mol Cell 2009, 36(2):231-244.

54. Fischer SE, Butler MD, Pan Q, Ruvkun G: Trans-splicing in C. elegans generates the negative RNAi regulator ERI-6/7. Nature 2008, 455(7212):491-496.

55. Ruby JG, Jan C, Player C, Axtell MJ, Lee W, Nusbaum C, Ge H, Bartel DP: Large-scale sequencing reveals 21U-RNAs and additional microRNAs and endogenous siRNAs in C. elegans. Cell 2006, 127(6):1193-1207.

56. Das PP, Bagijn MP, Goldstein LD, Woolford JR, Lehrbach NJ, Sapetschnig A, Buhecha HR, Gilchrist MJ, Howe KL, Stark R, Matthews N, Berezikov E, Ketting RF, Tavaré S, Miska EA: Piwi and piRNAs act upstream of an endogenous siRNA pathway to suppress Tc3 transposon mobility in the Caenorhabditis elegans germline. Mol Cell 2008, 31(1):79-90.

57. Bagijn MP, Goldstein LD, Sapetschnig A, Weick EM, Bouasker S, Lehrbach NJ, Simard MJ, Miska EA: Function, targets, and evolution of Caenorhabditis elegans piRNAs. Science 2012, 337(6094):574-578.

58. Lee HC, Gu W, Shirayama M, Youngman E, Conte D Jr, Mello CC: C. elegans piRNAs mediate the genome-wide surveillance of germline transcripts. Cell 2012, 150(1):78-87.

59. Luteijn MJ, van Bergeijk P, Kaaij LJ, Almeida MV, Roovers EF, Berezikov E, Ketting RF: Extremely stable Piwi-induced gene silencing in Caenorhabditis elegans. EMBO J 2012, 31(16):3422-3430.

60. Cox DN, Chao A, Baker J, Chang L, Qiao D, Lin H: A novel class of evolutionarily conserved genes defined by piwi are essential for stem cell self-renewal. Genes Dev 1998, 12(23):3715-3727.

61. Simon M, Sarkies P, lkegami K, Doebley AL, Goldstein LD, Mitchell J, Sakaguchi A, Miska EA, Ahmed S: Reduced Insulin/IGF-1 signaling restores germ cell immortality to Caenorhabditis elegans Piwi mutants. Cell Rep 2014, 7(3):762-773.

62. Wassenegger M, Heimes S, Riedel L, Sanger HL: RNA-directed de novo methylation of genomic sequences in plants. Cell 1994, 76(3):567-576.

63. Matzke MA, Mette MF, Matzke AJ: Transgene silencing by the host genome defense: implications for the evolution of epigenetic control mechanisms in plants and vertebrates. Plant Mol Biol 2000, 43(2-3):401-415.

64. Zaratiegui M, Castel SE, Irvine DV, Kloc A, Ren J, Li F, de Castro E, Marin L, Chang AY, Goto D, Cande WZ, Antequera F, Arcangioli B, Martienssen RA: RNAi promotes heterochromatic silencing through replication-coupled release of RNA Pol II. Nature 2011, 479(7371):135-138.

65. Dumesic PA, Natarajan P, Chen C, Drinnenberg IA, Schiller BJ, Thompson J, Moresco JJ, Yates JR 3rd, Bartel DP, Madhani HD: Stalled spliceosomes are a signal for RNAi-mediated genome defense. Cell 2013, 152(5):957-968.

66. Lee NN, Chalamcharla VR, Reyes-Turcu F, Mehta S, Zofall M, Balachandran V, Dhakshnamoorthy J, Taneja N, Yamanaka S, Zhou M, Grewal SI: Mtr4-like protein coordinates nuclear RNA processing for heterochromatin assembly and for telomere maintenance. Cell 2013, 155(5):1061-1074.

67. Dennis S, Sheth U, Feldman JL, English KA, Priess JR: C. elegans germ cells show temperature and age-dependent expression of Cer1, a Gypsy/ Ty3-related retrotransposon. PLoS Pathog 2012, 8(3):e1002591.

68. Brenner S: The genetics of Caenorhabditis elegans. Genetics 1974, 77(1):71-94.

doi:10.1186/1471-2164-15-1157

Cite this article as: $\mathrm{Ni}$ et al:: Complex coding of endogenous siRNA, transcriptional silencing and H3K9 methylation on native targets of germline nuclear RNAi in C. elegans. BMC Genomics 2014 15:1157.

\section{Submit your next manuscript to BioMed Central and take full advantage of:}

- Convenient online submission

- Thorough peer review

- No space constraints or color figure charges

- Immediate publication on acceptance

- Inclusion in PubMed, CAS, Scopus and Google Scholar

- Research which is freely available for redistribution

Submit your manuscript at www.biomedcentral.com/submit
() Biomed Central 